\title{
M-BUSINESS: NEGÓCIOS, TECNOLOGIAS E ESTRATÉGIAS
}

\section{M-BUSINESS: BUSINESS, TECHNOLOGIES AND STRATEGIES}

\author{
Data do recebimento do artigo: $8 / 06 / 2013$ \\ Data do aceite do artigo: 09/09/2013 \\ Data da publicação: $2 / 12 / 2013$
}

\author{
Prof. Dr. Luiz Claudio Gonçalves ${ }^{l}$ \\ Doutor em Engenharia de Produção \\ Fatec Zona Sul \\ Prof. Dr. Carlos Vital Giordano \\ Doutor em Ciências Sociais \\ Mestre em Administração \\ Fatec Zona Sul
}

\section{RESUMO}

As tecnologias de comunicação sem fio (wireless), irreversivelmente estão surgindo nos atuais ambientes de negócios. Facilidades como ubiqüidade e amigabilidade no uso fazem a sua aceitação ser praticamente imediata para usuários, desenvolvedores e profissionais de modelagem de negócios. Essas tecnologias despontam como a solução operacional, econômica e estratégica do século XXI e, segundo as previsões dos institutos de pesquisa, o volume de negócios gerados epas mesmas serão sensivelmente expressivos. Desse modo, o presente artigo, por meio de uma pesquisa bibliográfica e um estudo de caso busca apresentar e avaliar os impactos do m-business nas operações das empresas modernas.

Palavras-chaves: $m$-business, tecnologia sem fio, estratégia, inovação.

\section{ABSTRACT}

The wireless communication technologies are emerging irreversibly on current business settings. Facilities such as ubiquity and user friendliness do their acceptance being nearly immediate for users, professionals and developers business modeling. These technologies stand out as the operational solution, economic and strategic solution to the XXI century, and according to the research institutes predictions, the business amount generated will be considerably meaningful.

\footnotetext{
${ }^{1}$ Autor para correspondência: Universidade de Taubaté - Rua Expedicionário Ernesto Pereira, 225, Portão 2, CEP 12020-030, Taubaté, SP, Brasil.
} 
Thereby, this article, by a bibliographic research and a case study aims to present and evaluate the impact of $\mathrm{m}$-business operations of modern enterprises.

Keywords: m-business, wireless technology, strategy, innovation. 


\section{INTRODUÇÃO}

As tecnologias Móveis, Sem Fio e Ubíquas ${ }^{2}$ estão entre os assuntos mais discutidos na área de Sistemas de Informação atualmente. Com o crescimento da telefonia móvel, banda larga e redes sem fio, a mobilidade e a computação em múltiplas plataformas e aparelhos, tornam-se cada vez mais factíveis (Kalakota \& Robinson, 2002; Watson, Pitt, Berthon, \& Zinkhan, 2002). A indústria de TI tem realizado intensa divulgação dessas tecnologias, argumentando que essas viabilizam os assim chamados "Negócios Móveis" (m-business) (Fenn \& Linden, 2001; Kalakota \& Robinson, 2002).

Segundo os autores anteriormente citados, nota-se certo alinhamento das soluções empresariais em direção à Internet e das redes sem fio. Entretanto, algumas perguntas a se fazer: os negócios móveis vão acontecer? Em que extensão? E seu impacto nas empresas estabelecidas e naquelas que querem aproveitar a oportunidade para inovar?

Dessa forma, em busca de responder a essas perguntas, inicialmente o presente artigo busca realizar uma revisão visando elucidar as recentes definições sobre o tema, bem como avaliar onde os negócios com a nova tecnologia estão preliminarmente sendo realizados e qual a repercussão já alcançada. Parece evidente que inúmeras oportunidades estão surgindo, algumas aproveitadas outras em fase de análise de viabilidade. Entende-se o m-business como complementar ao e-business, trazendo novas aplicações móveis que possibilitam facilidades e rapidez sem precedentes no acesso à informação.

Em um segundo momento, o artigo procura avaliar as teorias discutidas em um caso real de implantação de uma solução m-business, cujo exemplo escolhido foi um sistema que controla o fluxo e os meios de pagamento de um restaurante situado na zona sul cidade de São Paulo. Por fim, são apresentadas algumas considerações finais, devidamente embasadas no referencial teórico e nos dados coletados no estudo de caso.

\section{TECNOLOGIA MÓVEL E M-BUSINESS (MOBILE BUSINESS)}

Para De Sordi (2003) a tecnologia móvel, encerra o uso de tecnologias e serviços de comunicações móveis para suporte à negociação de bens, serviços, informação e conhecimento nos diversos setores da economia, e serve de meio de conexão entre empresas e clientes. Como "Móvel" subentende portabilidade, que está com a pessoa. Além da portabilidade outro item

\footnotetext{
${ }^{2}$ A computação ubíqua envolve, em termos tecnológicos, a existência de diversos computadores interconectados por redes sem fios em cada ambiente, protocolos de comunicação que permitam o trânsito entre diferentes dispositivos e entre redes que se espalham pelos prédios, ruas, carros, em todos os locais (SACCOL \& REINHARD, 2007).
} 
importante é a conectabilidade: se o dispositivo está on-line, ligado a uma rede (Internet, rede corporativa, redes ad hoc, por exemplo) ou off-line, sem conexão alguma.

No ambiente empresarial, a incorporação de novos sistemas de informação aumenta a importância da interatividade de todos os participantes, esses novos requisitos, conforme argumenta De Sordi (2003), incluem a demanda por conexão fora de locais tradicionais, indo além das estações de trabalho fixas localizadas em escritórios e fábricas. Em ambientes com maior flexibilidade, e também para os clientes que não mais necessitam de computadores fixos, as soluções embarcadas em notebooks, personal digital assistance (PDA) e tablets, por exemplo, permitem a criação de novos serviços em que o tempo e a localização não são mais motivos para restrições. A conseqüência econômica mais significativa esperada dessa evolução será o aumento da interação, em tempo real, entre as empresas e seus clientes, seus funcionários e seus fornecedores.

Na visão de Kalakota e Robinson (2002), as aplicações móveis mudarão a maneira de todos nós vivermos, nos divertirmos e fazermos negócios. Esses autores destacam ainda que a computação móvel representa a primeira onda de aplicações a tirar proveito da tendência da computação ubíqua, apresentando duas fases distintas desse processo:

- Fase 1 (anterior): o usuário vai aonde o computador está (centrado no PC).

- Fase 2 (em desenvolvimento): o computador está onde quer que o usuário esteja (centrado na pessoa). O poder da computação vai para onde quiser, no ato, com máxima flexibilidade, e no ritmo que os negócios exigem.

A mobilidade necessária para a fase 2 exige tecnologias condizentes com esta característica. No contexto atual isto é conseguido com redes sem fio (wireless), sendo as tecnologias mais destacadas a comunicação por protocolos usados nos celulares, Wi-Fi e Bluetooth.

É importante salientar que a mobilidade, segundo Keller et al. (2000), relaciona-se com a portabilidade, por exemplo, acessar e-mails por meio de um smart phone de qualquer lugar. Todavia, essa mobilidade não significa dizer que o equipamento tenha sempre uma "conexão ligada". Em função de uma série de aspectos e padrões tecnológicos ainda em desenvolvimento é possível se observar duas formas da conexão entre um usuário em um local remoto e a sua empresa, por exemplo: on line (sempre conectado) e off line (conectado quando solicitado). O entendimento dessas duas situações possíveis será primordial para se projetar a aplicação de m-business e até entender limitações e possibilidades de expansão das aplicações. 
Outra forma de conexão móvel é via handheld, também chamado de PDA (Personal Digital Assistant) desde que possa ter acesso à Internet. Os handhelds são aparelhos do tamanho de um bolso capazes de manipular dados eletrônicos. Mas esta categoria de equipamento vem perdendo sua força no mercado, não por limitações de suas utilidades, mas por um fenômeno que também vai aos poucos diminuindo também o poder de vendas de aparelhos celulares, que é a convergência para um único dispositivo, chamado de smartphone. Este equipamento alia as capacidades de processamento e armazenamento de dados de um handheld aos recursos da telefonia móvel, sendo, portanto, a evolução natural destes dois dispositivos.

À medida que aumente a difusão das aplicações móveis e essas se tornem mais sofisticadas, parece inevitável a transformação do telefone celular em uma ferramenta totalmente integrada de dados, comunicação e comércio (KELLER et al, 2000). Também as WLANs (wireless local area netwok) estão espalhando-se rapidamente pelos escritórios das empresas, comunicações entre empresas e também, por ambientes dos mais diversos.

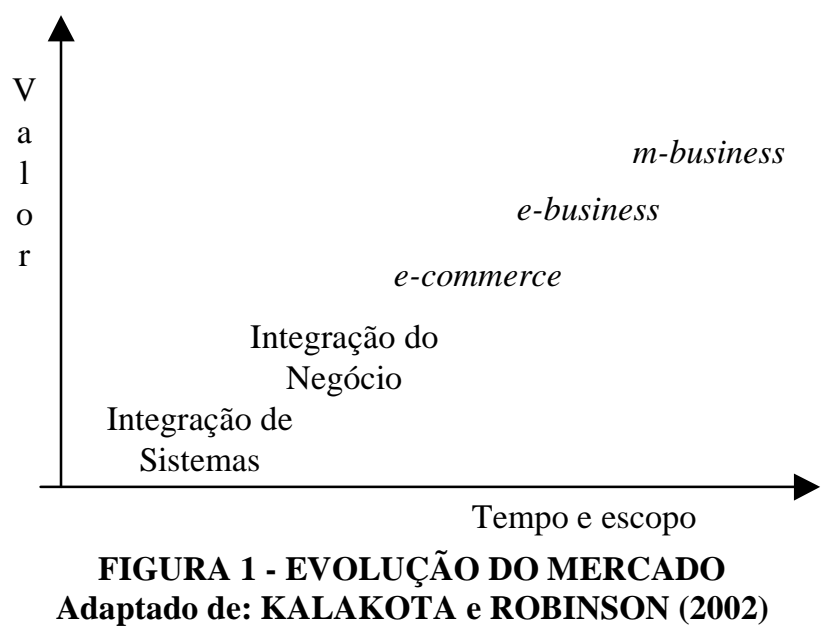

Os avanços da tecnologia sem fio em rede, o rápido desenvolvimento de soluções de negócios neste ambiente, o crescimento da Internet e o aumento do número de usuários dos dispositivos sem fio, estão propiciando o nascimento de um novo termo: o m-business (negócios móveis). Conforme Kalakota e Robinson (2002), o m-business é o resultado de uma rápida sucessão de mudanças estruturais nos negócios, que se iniciaram em 1995 (vide figura 1), e lembram que é posterior e complementador ao e-commerce e ao e-business.

O m-business pode também ser descrito como um comércio de A-para-A (A-to-A), ou @3: qualquer dispositivo, qualquer tempo, qualquer lugar (any device, anytime, anywhere). É diferente porque altera as dimensões espaciais dos negócios, levando a uma significativa transformação nas operações entre empresas e usuários. Representa a remoção das limitações ou 
restrições que existem no mundo "com fio", em especial as limitações de mobilidade, como nos dispositivos e redes fixas.

Porém, nem tudo são boas notícias, pois nas implantações feitas foram detectados alguns problemas, perfeitamente compreensíveis para uma nova tecnologia em fase de disseminação, que estão sendo devidamente equacionados para as novas versões: Tamanho das telas dos dispositivos (pequena), velocidade de comunicação (baixa), custo para o uso (caro), complexos para determinado tipo de usuário (facilidade de uso), conteúdos restritos e necessidade de uma transformação nos conteúdos para a próxima geração de soluções.

\section{TECNOLOGIA E ESTRATÉGIA EMERGENTE}

Tecnologias emergentes são inovações com base científica que detêm o potencial de criar um novo setor ou de transformar um já existente, ensinam Day e Schoemaker (2000). Contudo, esses autores lembram que é também útil distinguirem-se as tecnologias que são novas para as empresas, ou para uma unidade da empresa, daquelas que são novas para o mundo.

O surgimento de uma tecnologia desafiadora, como a tecnologia móvel, raras vezes se constitui em uma surpresa, argumentam Day e Schoemaker (2000b), porque a maioria dos administradores freqüenta conferências, lê a imprensa, compra estudos, conversa com clientes e, em geral, monitora os desenvolvimentos em sua área. Para os autores, a ambigüidade inerente a uma tecnologia emergente e os novos mercados que pode criar, conjugados com a dominância de estruturas decisórias tradicionais, tornam as empresas estabelecidas vulneráveis a armadilhas relacionadas e seqüenciais, que podem ocorrer em estágios diferentes do processo de decisão estratégica:

- Participação adiada - é tentador somente observar e esperar.

- Agarrando-se ao conhecido - precisam em algum ponto escolher se e como participar da tecnologia emergente.

- Relutância ao total compromisso - assumindo um comprometimento apenas indiferente.

- Falta de persistência - ao deparar com resultados adversos, retiram-se.

O trabalho para os gestores é contornar adequadamente estas armadilhas, que por serem seqüenciais e dependentes, indicam que a transposição de uma fase necessariamente não predispõe sucesso automático para as fases sucessivas. A cada passo, inicia-se novamente procedimentos de reavaliação e reafirmação de compromissos em busca do objetivo final. 
Já indústrias emergentes, segundo Porter (1986), são indústrias recentemente formadas, ou reformadas, criadas por inovações tecnológicas, alterações de custos relativos, surgimento de novas necessidades dos consumidores, ou outras alterações econômicas e sociais. Esse autor destaca ainda que, esse tipo de indústria elevam um novo produto ou serviço ao nível de uma oportunidade potencialmente viável de negócio.

Sob a ótica de Kalakota e Robinson (2002), o m-business é muito recente, mas sem dúvida é uma indústria emergente criada a partir da disseminação em marcha das redes sem fio, que na sua essência habilitam a convergência da Internet, negócios eletrônicos e mundo sem fio. Similar a outras indústrias emergentes, o m-business é caracterizado por mudanças contínuas em um ambiente complexo, que gera importantes incertezas em termos de tecnologia, demanda e estratégia.

- Tecnologia: as incertezas são tipicamente causadas pelo rápido desenvolvimento tecnológico, criação de padrões e aos estágios iniciais de consolidação de uma inovação.

- Demanda: a despeito do enorme potencial decantado para os negócios móveis, existem incertezas sobre serviços a serem desenvolvidos, aceitação dos clientes e o tempo efetivo de adoção da tecnologia.

- Estratégia: Porter (1986) lembra que uma característica essencial de uma indústria emergente, do ponto de vista da formulação estratégica, é que não existem regras neste jogo. Tem-se ainda que, quando uma indústria começa a desenvolver-se o poder de atração para novas empresas pode ser acentuado. Além disso, a complexidade presente nas aplicações e serviços requerem competências competitivas específicas.

Assim, a empresa talvez necessite alterar a estratégia se ocorrerem grandes mudanças estruturais no setor, conforme menciona Porter (1999). De fato, novas posições estratégicas geralmente derivam de mudanças setoriais, exploradas com mais facilidade pelos novos entrantes, desonerados dos fardos da história.

Buscando modelar o ambiente competitivo e estratégico do setor, Camponovo (2003) declara que o mercado de m-business é bastante fragmentado e que demanda colaboração contínua entre as diferentes empresas. Esse mesmo autor apresenta uma classificação procurando colocar cada ator em um grupo, para melhor elaborar uma estratégia para o setor (vide figura $2 \mathrm{e}$ modelo detalhado no anexo A). Uma empresa atrelada a uma solução e fazendo parte de um grupo, pode em outra situação, prestar os mesmos serviços para uma outra configuração de grupo, com empresas diferentes às do grupo anterior, indicando a proposição de estratégias comuns a mais de uma empresa dentro do setor. 


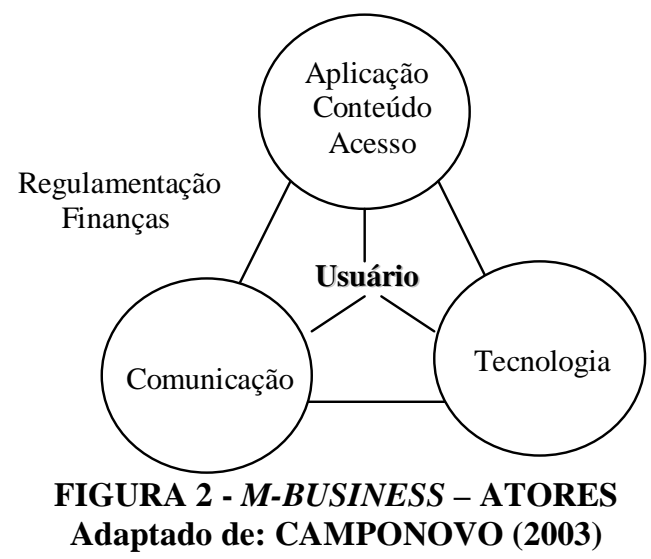

Para Porter (1986), a formulação da estratégia em indústrias emergentes necessita levar em conta a incerteza e o risco deste período de desenvolvimento. Esse mesmo autor alerta que as regras do jogo competitivo são muito indefinidas, a estrutura da indústria ainda não está estabelecida e, provavelmente está sofrendo mudanças.

Já Dyer e Singh (2000), argumentam que em cenários em que há necessidade de fortes laços de relacionamentos tanto acima (jusante) como abaixo (montante) na cadeia de suprimentos, a solução mais recomendada é o desenvolvimento de uma aliança estratégica, a qual desempenha um papel central no sucesso de empresas de tecnologias ou indústrias emergentes. Esses autores definem aliança estratégica como sendo um relacionamento cooperativo entre duas ou mais organizações, projetado para alcançar um objetivo estratégico compartilhado, dividindo e aperfeiçoando as incertezas.

Em outra abordagem, Porter (1999), destaca que o desenvolvimento da estratégia em um setor emergente ou numa empresa que esteja passando por mudanças tecnológicas revolucionárias é uma proposta assustadora. Isso ocorre em virtude das incertezas sobre as necessidades dos clientes, sobre os produtos e serviços mais desejáveis e sobre a melhor configuração das atividades e tecnologias, com vistas ao seu atendimento. Ao final conclui que incapazes de correr o risco de errar ou de ficar para trás, as empresas emulam todas as características, oferecem todos os novos serviços e exploram todas as tecnologias, evidentemente não optando por quaisquer abordagens excludentes.

Em termos de estratégia empresarial, Kalakota e Robinson (2002) salientam que o mbusiness tem um enorme potencial para renovar os produtos e serviços de uma empresa e simplificar seus processos. Porém, o processo de desenvolvimento de uma estratégia é longo, detalhado e difícil. Não pode ser simplesmente comprado e instalado. Enfatizam que antes que se 
possa perceber quaisquer benefícios da mobilidade, ela precisa se tornar integrada com a maneira dos usuários e da empresa fazerem as coisas.

\section{ESTUDO DE CASO}

\section{Dados da empresa:}

Empresa: Restaurante localizado na zona sul de São Paulo.

Tecnologia: rede wireless Wifi e Bluetooth, pontos de acesso, rede LAN (local area network) fixa, servidor de aplicações, servidor de comunicação, conexão X25, parceiro para conexão as empresas de cartão de crédito e sistema de controle total do negócio.

Processo de Funcionamento: o garçom de posse de um iPaq com interface Wifi toma o pedido do cliente. O aplicativo rodando no iPaq, comunica-se por meio da WLAN com o ponto de acesso que permite a transmissão e recepção de dados com a rede fixa. No caso do pedido os aplicativos interligam-se e a transação é passada para a cozinha, para a contabilidade da conta e para outros setores interessados. Estando o prato pronto o pessoal da cozinha informa ao sistema que sinaliza na tela do iPaQ do garçom interessado que seu pedido está pronto.

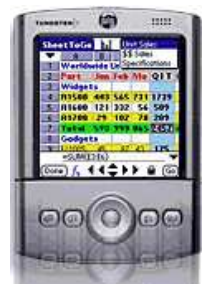

FIGURA 3 - HAND HELD

Ao encerrar a conta o garçom pergunta ao cliente a forma de pagamento. Sendo em cartão de crédito, o cartão é passado no dispositivo adaptado ao cinto do garçom que lê o cartão, comunica-se com o iPaq por Bluetooth e o iPaq comunica-se com a rede por WiFi. O servidor de comunicação entra em contato com o parceiro que intermedia as conexões com as operadoras de cartão de crédito, passando os dados do cartão e o valor. Se aprovado, o caminho das comunicações se inverte, indo do servidor de comunicação para o iPaq e daí para o dispositivo no cinto do garçom que além de leitor de cartão é também uma impressora, que emite o recibo da 
transação. No caso de cartão de débito, no dispositivo que encontra-se no cinto do garçom existe um teclado para digitação da senha.

Todas estas operações são devidamente monitoradas pelo sistema principal do negócio que controla a operação para posteriores análises financeiras, contábeis e gerenciais.

Existe a possibilidade de em um futuro próximo, a rede sem fio ser disponibilizada para os clientes utilizarem livremente a Internet (hotspot) ou outras redes, por meio de equipamentos que os próprios clientes portarem.

Aplicando a modelagem de Camponovo (2003) tem-se:

Aplicação, conteúdo e acesso - empresas* que desenvolveram os aplicativos e sistemas para os iPaq, para o sistema de controle e gestão e para as comunicações.

Comunicação - empresa* que fornece o acesso X25 ao parceiro intermediador com as operadoras de cartão de crédito. Poderia ser wireless, CDMA, por exemplo.

Tecnologia - computadores*, hand helds*, dispositivos Wi-Fi* e Bluetooth*.

Regulamentação* e finanças.

*Empresas ou entidades que devem rever suas estratégias em função da nova tecnologia aplicada. É uma forma nova de gerenciar negócios, revolucionária, altera drasticamente como os eventos acontecem.

\section{CONSIDERAÇÕES FINAIS}

As empresas devem avaliar claramente o potencial real de negócios no mundo wireless. Esse tipo de indústria é nova e está em fase de experimentação. Os negócios nesse contexto ainda não provaram ser devidamente sustentados, devendo ser continuamente monitorados. A tecnologia é emergente e ainda não há regras estratégicas claras para encaminhamento do planejamento.

Hoje, o m-business ainda está no campo da euforia e do potencial. Existem poucos exemplos de histórias de sucesso. Como também ainda não existem modelos anteriores de como fazer o desenvolvimento de uma estratégia móvel.

Pelas características apresentadas, o m-business aparenta ter impacto significativo nos modelos de negócios e nas estratégias das empresas modernas, requerendo competências 
adequadas a cada parceiro no setor. Uma união, coalisão ou forte parceria se torna crucial em função da quantidade de atores requeridos para a solução completa. As forças do lado do fornecedor e do cliente podem ter de ser reavaliadas. Dentro desse contexto, o desenvolvimento de alianças tornam-se uma boa opção estratégica.

$\mathrm{O}$ m-business promete libertar as pessoas de locais fixos e oferecer ferramentas valiosas para a melhoria das comunicações, coordenação e colaboração entre empresas, reduzindo custos e melhorando a eficiência do mercado, fazendo com que a informação esteja disponibilizada em qualquer dispositivo, em qualquer lugar e a qualquer tempo.

As aplicações possíveis não ficam reduzidas ao critério dos desenvolvedores de soluções. Por tratar basicamente de serviços, o potencial é inimaginável. Os clientes com seus dispositivos podem, a qualquer momento participar do processo de negócios. Esses estão simplesmente conectados todo o tempo.

$\mathrm{O}$ m-business como indústria é recente e as empresas participantes do processo ainda estão experimentando suas estratégias com diferentes modelagens de negócios, em busca de uma posição lucrativa e sustentada.

\section{REFERÊNCIAS}

CAMPONOVO, Giovanni. Mobile commerce business models. The University of Lausanne, 2002. Disponível em http://inforge.unil.ch/aosterwa/Documents/workshop/Camponovo.pdf. Acessado em 03/05/2013.

DAY, George S.; SCHOEMAKER, Paul J. Um jogo diferente. In: Gestão de tecnologias emergentes: a visão da Wharton School. Porto Alegre: Bookman, 2000.

Evitando as armadilhas das tecnologias emergentes. In: Gestão de tecnologias emergentes: a visão da Wharton School. Porto Alegre: Bookman, 2000 b.

De SORDI, José O. Tecnologia da informação aplicada aos negócios. São Paulo: Atlas, 2003.

DYER, Jeffrey; SINGH, Harbir. Utilizando alianças para construir vantagem competitiva em tecnologias emergentes. In: Gestão de tecnologias emergentes: a visão da Wharton School. Porto Alegre: Bookman, 2000. 
FENN, J., \& LINDEN, A. (2001). Trends for 2002 to 2007: up the slope of enlightenment. Gartner Group Article Top View. Disponívem em: http://www.gartner.com/ DisplayDocument?doc_cd=103538. Acesso em 19/05/2014.

KALAKOTA, Ravi; ROBINSON, Marcia. m-business: tecnologia móvel e estratégia de negócios. Porto Alegre: Bookman, 2002.

KELLER, Philip et al. M-commerce and Strategic Innovation, $20^{\text {th }}$ Intl Conference Strategic Management Society, Vancouver, October. Disponível em URL: http://www.hec.unil.ch/yp/Pub/00-sms.pdf. Acesso em 18/05/2014.

PORTER, Michael E. Estratégia competitiva: técnicas para análise de indústrias e da concorrência. Rio de Janeiro: Campus, 1986.

O que é estratégia. In: Competição. Rio de Janeiro: Campus, 1999.

SACCOL, Amarolinda Zanela; REINHARD, Nicolau. Tecnologias de Informaçăo Móveis, Sem Fio e Ubíquas: Definiçőes, Estado-da-Arte e Oportunidades de Pesquisa. RAC, v. 11, n. 4, p.175-198, Out./Dez. 2007.

WATSON, R., PITT, L., BERTHON, P., \& ZINKHAN, G. U-commerce: expanding the universe of marketing. Journal of the Academy of Marketing Science, 30(4), 329-343, 2002. 
ANEXO A

MODELO PARA APLICAÇÕES M-BUSINESS

Camponovo (2003)

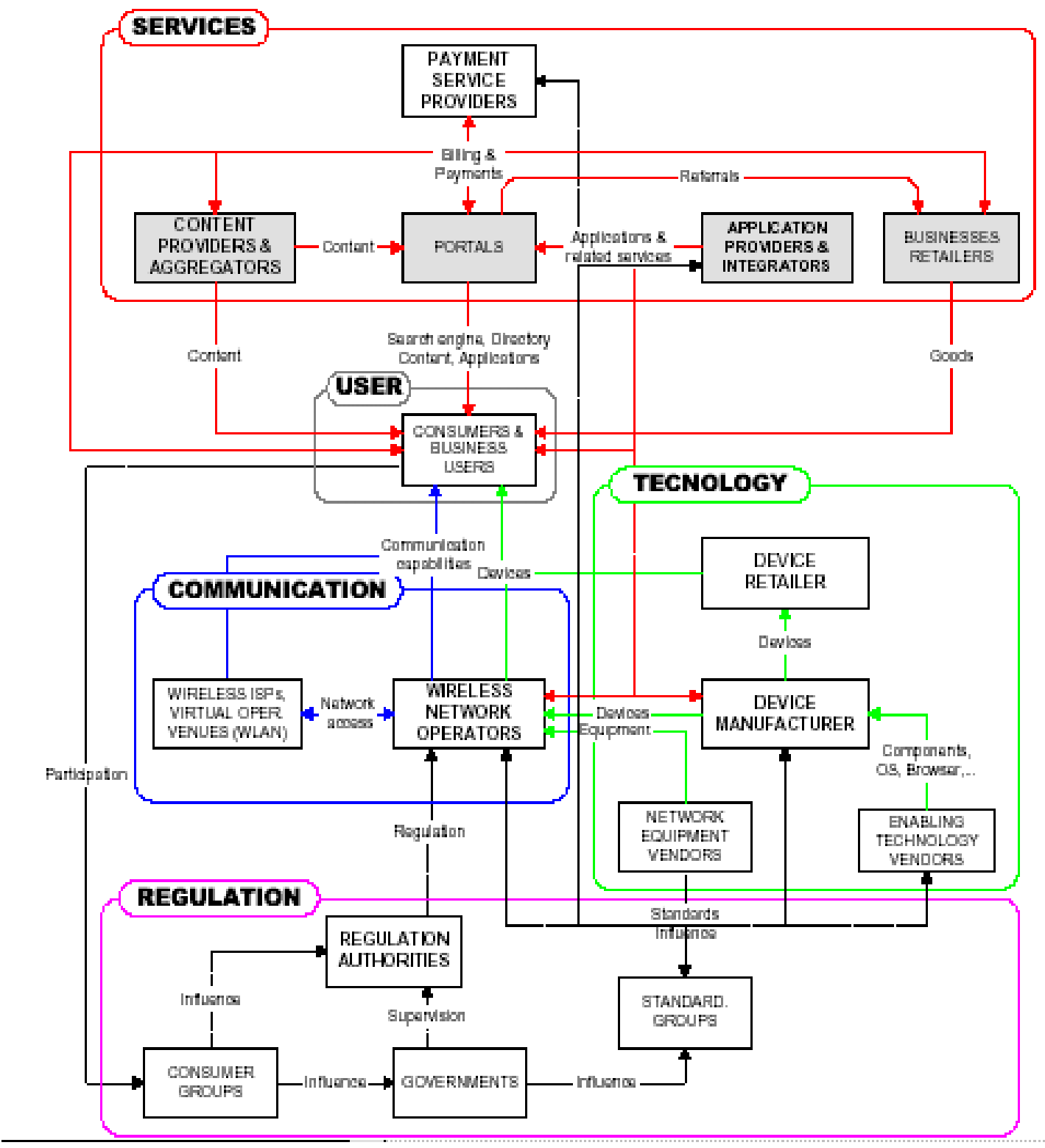

ENIAC Pesquisa, Guarulhos (SP), p. 96-108, v. 2, n. 2, jul.-dez. 2013. 